\title{
IS B2B MARKETING STILL ACTUAL?
}

\author{
Codrin TEIU \\ Alexandru Ioan Cuza University of Iasi \\ Faculty of Economics and Business Administration \\ codrin.teiu@gmail.com
}

\begin{abstract}
This paper is looking at the B2B email marketing activity of the last two years of enterprise level companies using major enterprise level software for marketing automation. We are looking to assess whether the industry of email is declining or increasing and how was that reflected in the database size and number of platforms used for the purpose of sending emails. We will evaluate based on data whether companies are increasing their efforts in email marketing or if the new media platforms, like for example social media have taken communications away from emails to new systems.
\end{abstract}

Keywords: Eloqua, email marketing, marketing automation

JEL classification: L86, M31

DOI: $10.12948 / \mathrm{ie} 2019.04 .11$

\section{Introduction}

With the development of the World Wide Web having a digital presence is a must. This was all there was to it in the beginning, when most marketing was outbound and there were no optimizations done.

As technology evolved companies started having available specialized software to aid them with their online marketing efforts. By this time, most companies were already familiarized with CRM (Customer Relationship Management) software and MAS (Marketing Automation Systems) appeared as part of the CRM family due to their complimentary nature towards a CRM. A software for enterprise level marketing automation is centered around an email sending engine with the purpose of nurturing leads through complex email marketing campaigns in order to get them interested in the products advertised to the point where they would qualify (by internal subjective criteria) to be send to the CRM so a sales team can start engaging with them.

This type of interaction with customers, by email, was and still is of actuality, though post 2010 when the rise of the social media networks became more and more obvious on the B2B side, many companies starting to be present on social media, there is the question whether email communication is becoming obsolete and whether companies still invest in it.

In order to answer this question, we will analyze the investment done in purchased platforms and database size while correlating them with the number of sent emails, over the last two years for major enterprise software system of such nature. We will be using Oracle Eloqua data as this is a leading software tool for B2B marketing automation.

\section{Email marketing evolution}

Marketing has been with us in more or less acknowledged forms since the first sale of a product. Email has appeared with after the first networks were present. The ability to send a message through a network proved to be an efficient way of communication as it is fast and it is cheap. 
The history of the email is a different thing than the history of email marketing. While email by itself mostly involves two end users communication to one another, email marketing is a communication between a company and end user, which may in fact represent another company, thus the B2B (business to business) naming.

The name forever tied to first email marketing campaign is Gary Thuerk, a marketing manager who in 1978 send an email promoting digital equipment machines to 400 users via Arpanet (an early network, it became technical foundation for the Internet). It resulted in 13 million dollars in sales and got Thuerk the name of "Father of Spam" [1].

Hotmail has opened the gate for email in 1990 when they launched the online email service which was free. Anybody could have opened an account and it gave marketers a new way to reach out to customers. This was still new at the time, but more and more marketers started to use is to engage with its possible customers. As it was a still unregulated area, the inboxes started to become full of unsolicited emails.

The year 1998 brings the Data Protection Act which is the first regulation in this area which was the mandatory rule for the sender to allow opt-out from emails. This was later on enforced in 2003 by the Can Spam Law in the United States.

The year 2004 comes with the first validation protocol, the Sender Policy Frameworks which validates a sender by IP address. Basically this is the year in which sender became unable to send emails on behalf of domains which did not authorized them previously without being flagged for doing so [2].

By the start of the 2000's Internet Service Providers introduced a range of methods to protect their customers from unsolicited email. Return Path has estimated in 2009 that over one third of commercial emails did not arrived in the inbox, while the most reported issue was the lack of relevance of the communication and recipients decided to opt-out.

The launch of the first smart phones and the 2007 iPhone has enabled access to email by using the mobile. The possibility to reach out to customers on their mobile increased the reach of the email technology as it started "walking" with people. By 2012 over $40 \%$ of emails were opened on a mobile device, which also led to advancements in email design and email optimization for mobile devices.

Facebook launched publicly in 2006 but it took to after 2010 to become the world wide tool which is today. Even so, as early as a year after launch it had over 100k business profile pages. Email was not anymore the easiest or the one with the highest reach.

With all the channels for communication open to engage with a brand, like social media, email, in store, on website, the amount of data recorded during all these interactions has dramatically increased. Companies started realizing the importance of collecting and managing this data in order to gain competitive advantage and better predict customer behavior [3].

This is the starting point of behavioral led programs in marketing automation, of dynamic emails and landing pages, of personalized communications as opposed to the standard newsletter approach email strategy. It all started as a mass marketing strategy and has evolved into a complex behavioral strategy for companies to develop their brand and anticipate the needs of the customer. The online near one to one experience is nowadays the spearhead of marketing automation.

\section{Oracle Eloqua marketing automation solution}

Oracle Eloqua is a marketing automation system dedicated for B2B customers. This is a paid software tool, most often integrated with a CRM, which at its simplest description is facilitating a company's need to manage its email communications towards contacts in their database. These contacts are from other companies and are primarily decision makers in the buying process of the company they are part of. 
A customer can buy this tool in several licensing versions, most often one purchase allowing for multiple platforms to configure. A common use case is splitting different kind of email communications in different platforms, for example transactional emails (like purchase receipts, password change emails, etc.) or internal communications emails (like from the human resources department) or emails dedicated to nurture customer contacts. One of the reasons to do so is to get accurate metrics for each, as they can have really different results. For example the open rate of transactional emails is very high as most people will wait for and open the email to help them change a password or read a receipt, while an email promoting a product is less likely to be opened.

In its highest licensing form, Eloqua allows for 20 such platforms at once. At the core of the product sits the email sending engine and the software tools to create complex contact nurture flows. The personalization modules allow near one to one communications towards the contacts, while other components like the lead management one which allows for segmentation, lead nurture and CRM integration [4].

The product also allows integrations in order to benefit of your website data. Website pages can be tracked and that info made actionable in the tool. The social media side is also present with different integration possibilities with the main social media platforms like WeChat, Facebook and LinkedIn.

Lastly the reporting and analysis component takes benefit of the data collection process and displays this data in various reporting formats to help decision makers improve on their communication strategies.

\section{Product usage activity}

The main question which we are looking to answer is whether email marketing usage in the $\mathrm{B} 2 \mathrm{~B}$ sector is increasing or decreasing in the context of the rise of the presence of companies is social media. It is a legitimate question to ask ourselves whether the marketing budget is switching to social media side of marketing or if that is complimentary and companies are still investing in email.

I believe a good indicator for this question is gauging the size of the databases used in email marketing in correlation with the number of sent emails and platforms used. Given that all these are paid items, an increase or decrease would directly tie to the budget invested in this marketing path.

The database size is directly correlated with the number of email sends as long as best practice marketing is applied. Most companies define for themselves the highest number of emails a contact can receive in a certain amount of time. This is also depended of ISP's as some of them would flag as spam if a contact is receiving too many emails from the same sender within a certain amount of time. A common limit is no more than 6 emails within a month, while in some cases it can go to up to 10 emails a month for the same contact.

More than 11 emails a month to the same contact usually indicates a lack in using best practice email marketing campaigns and will come with the cost of being flagged as spam and harming you sender reputation or not having proper inbox placement and your messages are not being read.

Even so, many companies are uploading all the contacts they have into the database and don't account for actionable segmentation criteria. This results in many of those contacts being never selected when segmenting for email recipients because they don't fall within the criteria. This kind of contacts should at least be engaged with welcome campaigns and opting in emails in order to confirm their subscription and keeping them active. 
www.conferenceie.ase.ro

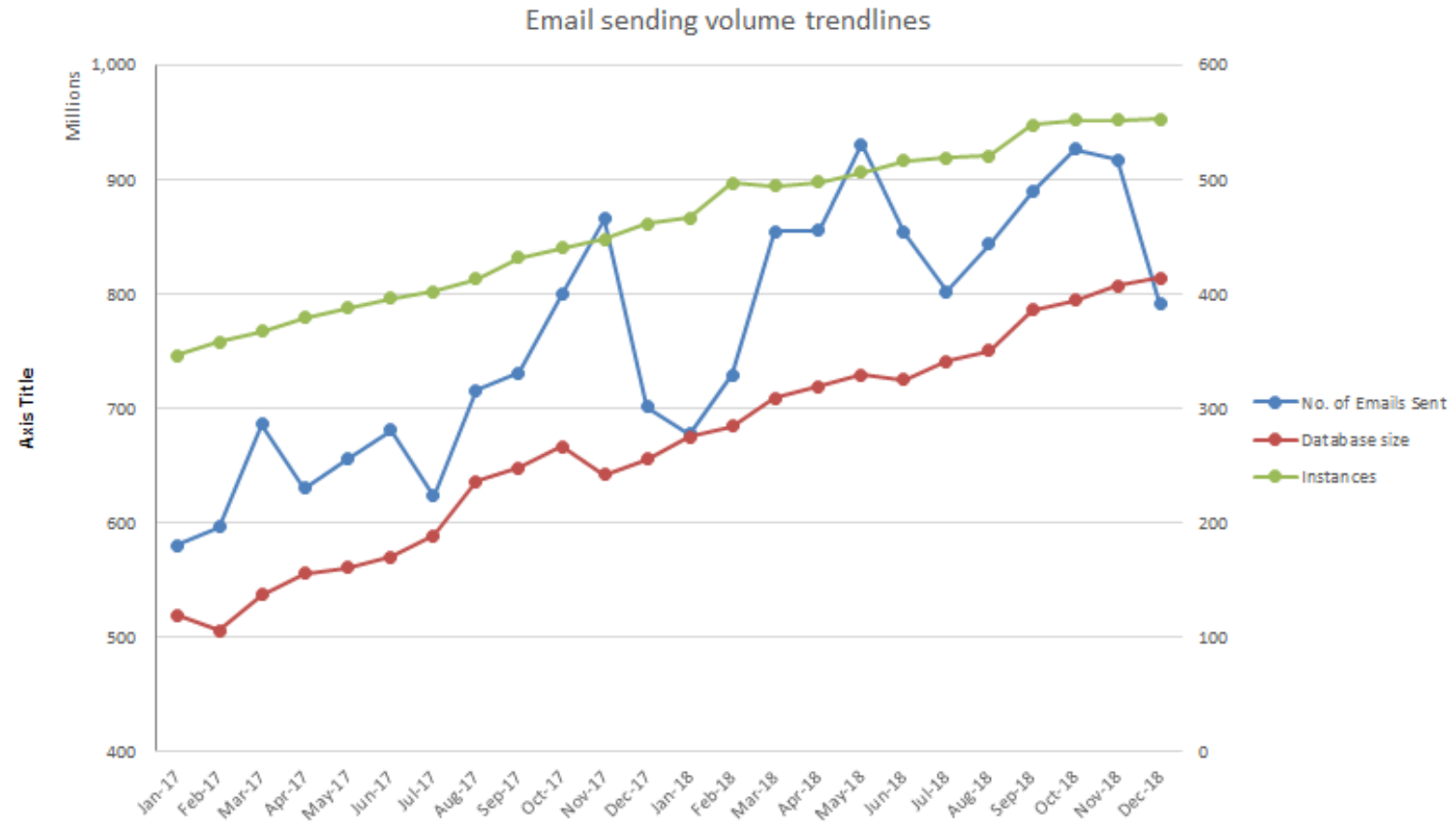

Figure 1. Sending volume evolution

The above graph is showing the evolution of the database size, number of email sends and platforms (many times referred to as instances) used by customers of Oracle Eloqua.

The time span for this analysis is from January 2017 to December 2018.

The database size is a sum of all the contact databases of all enterprise level customers. The number of emails sent is a sum of all emails sent by all customers, per month. The number of instances is the number of individual Oracle Eloqua platforms used to store the contact databases and send the emails.

We can notice in the last two years an increase in the number of instances used, from 346 to 552. The 346 instances to start with correspond to about 150 different customers which means that at the start of this analysis one customer was using at least 2 different platforms for their marketing automation campaigns. The increase of over 55\% in the number of platforms used tells us that in two years customers are using about three different platforms, in comparison with just 2 when this analysis starter. The most likely cause for this is a diversification of the email campaigns and data management. Most probably customers are having separate platforms to manage customer contacts communications where they nurture leads and send them to the CRM for sales to engage with, another of for transactional or blast emails and most probably a third for internal use or human resources use. There is also the high likeliness for them to have separate brands or divisions and having them on boarded to marketing automation in standalone platforms.

The database size is a good indicator for budgets as database size is per contact. The higher the number of contacts in the database is the higher the investment becomes. The graph is showing database size in millions of contacts. In January 2017 the combined database size was at 519 million contacts. That has increase with close to $60 \%$ in two years to up to 813 million contacts. It has steadily increased from month to month, with small exceptions in just three cases when in decreased from one month to the next. It is common for customers of such products to perform database cleanups every 6 months to one year. The database cleanups are usually directed to unreachable contacts or to contacts who don't engage with the company's communications at all during a certain period of time. 
www.conferenceie.ase.ro

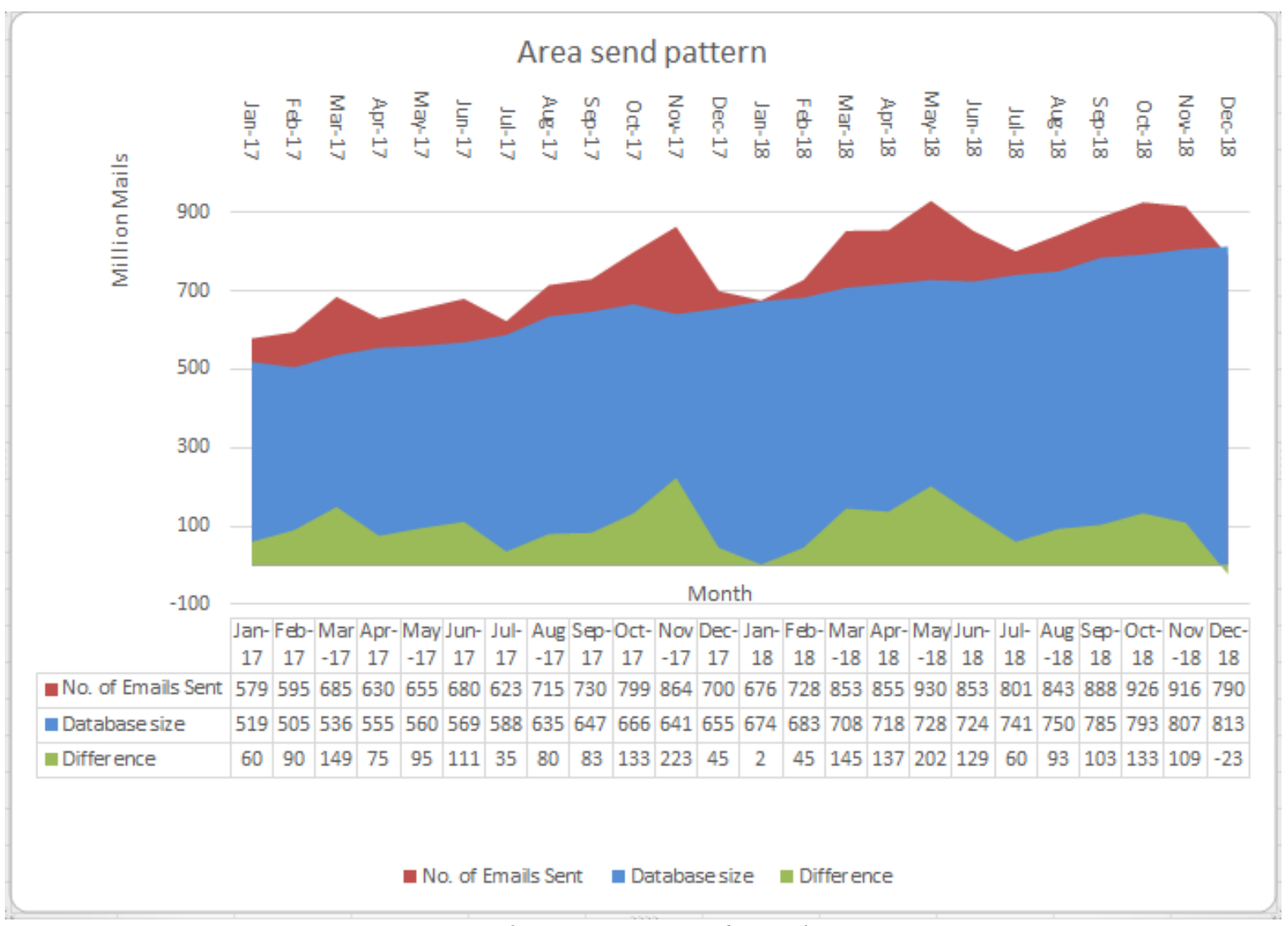

Figure 2. Variation in sending volumes

The number of sent emails represents the summed up email sending volumes per month for all the platforms combined. It is 579 million emails in January 2017 going towards the 800 million plus email a month towards the end the 2018, with a peak of over 926 million in October 2018 most probably in anticipation of the Black Friday event.

The highest variation between database size and number of send emails was in November 2017 when the number of send emails was 223 million more than the number of database contacts. The smallest variation was in January 2018 and it was just 2 million.

What I find surprising in these numbers is how close the database size to the number of sent emails is. Usually, sending one to two emails a month to the same contact is counted as service underutilization. A healthier database size to sending volumes ratios is three to 5 times the database size in matters of sending volumes. To most measure it means that companies are storing their databases and paying for that storage but are using a fraction of the contacts they can use, as we don't have the certainty that all contacts received at least one email within one month. A common case is where a customer is usually emailing less that $40 \%$ of its database on a regular basis. This has to do with segmentation and with marketing strategies which don't encompass contacts at various stages of information within the database.

A calculated correlation coefficient (using the correl() function in Excel) between the arrays of database size and number of sent emails is 0,857 , which indicates a strong positive relationship. The existence of this positive relationship does not mean one variable is causing the change in the other, in other words correlation is not causation, but is shows that the evolution of one is following the same positive trend as the others. 
www.conferenceie.ase.ro

\section{Conclusions}

In conclusion, email marketing is on an ascending trend. As we previously stated, our indicator is database size and number of instances in use, as they are directly connected to purchasing such software. The product itself, Eloqua, has become one of the most complete solution in its class.

It appears that the presence of social media has not made companies to decrease their investment or usage of email as a tool of reaching out to their customers, but on the contrary we see an average of over 50\% increase in the last two years in both investment and usage. There is also a high positive correlation between the increase in database size and the number of sent emails.

This data tells us that companies are most probably budgeting social media separately, which according to best practices [5] makes sense. A common flow is source attribution within the CRM once a lead is there. Having email and social media as different sources can make it easier to calculate the return of investment of each.

This short analysis opens the study path for additional more interesting use cases, like adding to the picture the results of these emails sends, meaning factoring in data for email opens and emails clicks and data for contact unsubscribe or spam reporting. Another line or research, more in line with this paper would be measuring the number of active contacts within the platforms taken into account, after defining a common grounds definition for what active means.

\section{References}

[1] Expert commentator on SmartInsights, "The evolution of email marketing," Available at: https://www.smartinsights.com/email-marketing/email-communications-strategy/emailmarketing-evolution/, May 24, 2013 [Accessed: April 11. 2019]

[2] S. Jenkins, "The truth about email marketing," USA, 2008, [Online], Available at: https://books.google.ro/books?id=0SIyOq9qu68C\&lpg=PR7\&ots=KkQhNQX_06\&dq=b $2 \mathrm{~b} \% 20$ email\%20marketing\&lr\&hl=ro\&pg $=\mathrm{PR} 4 \# \mathrm{v}=$ onepage $\& \mathrm{q}=\mathrm{b} 2 \mathrm{~b} \% 20 \mathrm{email} \% 20 \mathrm{mark}$ eting \&f=false, [Accessed: April 11, 2019]

[3] K. Bodnar, J. L. Cohen, "The b2b social media book," USA, 2011, Available at: https://books.google.ro/books?id=wvDV10uo6R8C\&lpg=PT13\&ots=79WW1si-

$\mathrm{bK} \& \mathrm{dq}=\mathrm{b} 2 \mathrm{~b} \% 20$ email $\% 20$ marketing $\& \mathrm{lr} \& \mathrm{hl}=\mathrm{ro} \& \mathrm{pg}=\mathrm{PT}$ $\# \mathrm{v}=$ onepage $\& \mathrm{q}=\mathrm{b} 2 \mathrm{~b} \% 20 \mathrm{email}$ $\% 20$ marketing\&f=false, [Accessed: April 8, 2019]

[4] Marketing Automation - Eloqua, Product details, Available at: https://www.oracle.com/marketingcloud/products/marketing-automation/index.html, [Accessed: April 7, 2019]

[5] G. Holliman, J. Rowley, "Business to business digital content marketing: marketers' perceptions of best practice," Journal of Research in Interactive Marketing, vol. 8, 2014, pp. 269-293, Available at: https://e-space.mmu.ac.uk/579029/

[6] Oracle blogs, "Gartner magic quadrant report," 2018, Available at: https://blogs.oracle.com/marketingcloud/oracle-gartner-mq-crm-lead-management-2018 [Accessed: April 9, 2019] 